\title{
The impact of parental history on children's risk of asthma: a study based on the National Health and Nutrition Examination Survey-III
}

This article was published in the following Dove Press journal:

Journal of Asthma and Allergy

25 May 2015

Number of times this article has been viewed

\author{
Rengyi Xu' \\ Sara B DeMauro² \\ Rui Feng' \\ 'Department of Biostatistics and \\ Epidemiology, Perelman School \\ of Medicine at the University of \\ Pennsylvania, Philadelphia, PA, USA; \\ ${ }^{2}$ Division of Neonatology, Perelman \\ School of Medicine at the University \\ of Pennsylvania and The Children's \\ Hospital of Philadelphia, Philadelphia, \\ PA, USA
}

Purpose: This study aimed to examine the separate effects of maternal and paternal history on the onset of asthma in children and evaluate the relationship between age of asthma onset in parents and risk of asthma in their children.

Methods: We used data from the third National Health and Nutrition Examination Survey. We developed new continuous standardized scores for survey data to quantify parental history that incorporated both the occurrence of asthma and the age at onset, and associated these scores with asthma risk in the children. The association analysis was adjusted for sex and obesity status.

Results: Children with maternal history have elevated asthma risk (hazard ratio of 3.71, 95\% CI: 1.19-11.60) than those without, and those whose mothers had earlier age of onset have increased risk of asthma compared to those whose mothers had later age of onset. On the contrary, paternal history had a relatively smaller effect that may be only detectable in larger samples (hazard ratio of 2.17, 95\% CI: 0.69-6.79).

Conclusion: Maternal asthma history was strongly associated with the onset of asthma in the second generation, and children whose mother had an earlier age of onset had an increased risk of 3.71. For an approximately 10-year decrease in mother's age at onset of asthma, the risk of asthma for the offspring increased by 1.37 -fold. Using our new risk scores led to smaller standard errors and thus more precise estimates than using a binary indicator.

Keywords: parental history, asthma risk, maternal history, survey, family data

\section{Introduction}

Asthma, a chronic respiratory disease, affects about $10 \%$ of adults and up to $30 \%$ of children. ${ }^{1,2}$ Multiple demographic, environmental, and genetic factors, including sex, obesity, smoking history, exposure to air pollution, several genes in the lung development pathway, and family history, have been found to be associated with increased risk of asthma. ${ }^{3-9}$ Asthma is inheritable, and many studies have found elevated risk associated with a positive parental history of asthma, positive first-degree relatives' history of asthma, and the number of affected relatives. ${ }^{10-12}$ Further investigations of causal genetic variants underlying the disease have found that multiple genes such as fatty acid desaturase 2 (FADS2), $N$-acetyl-a-D-galacto-saminidase (NAGA), and Factor XIII, A1 (F13A1) are linked to asthma, though each only contributes a little to asthma risk. ${ }^{13}$

Because the observed familial segregation of asthma cannot be completely explained by additive genetic models, alternative mechanisms have been proposed. Recent epigenetic studies found that prenatal environmental stimuli, including
Correspondence: Rui Feng

Department of Biostatistics and Epidemiology, University of Pennsylvania Perelman School of Medicine, 209 Blockley Hall, 423 Guardian Drive, Philadelphia, PA 19104, USA

Tel +I 2157464473

Fax +I 215 5731050

Email ruifeng@mail.med.upenn.edu 
maternal smoking, can alter DNA methylation and lead to the development of asthma, suggesting that maternal status might be more relevant to the offspring's risk. ${ }^{14,15}$ Several studies have evaluated the separate effects of maternal and paternal asthma history on the offspring's risk, but reported conflicting results. While some found maternal history to be more strongly associated with children's asthma risk than paternal history, ${ }^{16,17}$ a few others concluded that the association was stronger with paternal history. ${ }^{18,19}$

Most existing studies in this area had small sample sizes and all used a binary indicator of whether the mother or father had asthma or not as a measure of parental history, which may not be optimal to provide sufficient power or accuracy to quantify disease history. We aimed to examine the association between parental history and the onset of asthma in the second generation in a large national survey. In addition to the commonly used binary indicator, we proposed a continuous standardized risk score to incorporate the mother's and father's age at onset of asthma into the risk assessment of maternal and paternal histories. This score, similar to that in Feng et al, ${ }^{20}$ yet specific to the complicated survey data, is expected to improve prediction of risk in the second generation. We hypothesize that maternal history may contribute more to the asthma risk of their children than does paternal history and investigate this closely in our study.

\section{Materials and methods NHANES}

The National Health and Nutrition Examination Survey (NHANES) is conducted annually to assess the health and nutritional status of adults and children in the United States. The process consists of two parts: a household interview to collect demographic, socioeconomic, and health information; and a physical examination to collect medical, dental, and physiological measurements. In order to obtain a nationwide representative sample, NHANES uses a complex, multistage, probability sampling design. The sampling is carried out by first selecting primary sampling units (PSUs). In most cases, the PSUs are defined to be counties. The PSUs are then grouped into strata, and neighborhoods are selected within each stratum. Within each neighborhood, households are randomly selected, and inhabitants in the households are interviewed to determine their eligibility to participate in the survey. Since participants within each stratum are more likely to share similar characteristics, we need to adjust for the correlation within the strata in our analysis. To account for the complex survey sampling design, nonresponse and poststratification, NHANES also assigns a statistical weight to every individual. Given the complicated survey sampling design, traditional statistical methods do not apply to analysis of the NHANES data. Thus, we took the complex sampling design into consideration by specifying the sampling design parameters to obtain unbiased estimates, as described below.

For this study, we used the household adult and examination data files from the third NHANES (NHANES III), conducted from 1988 to 1994. We chose NHANES III instead of more recent NHANES data sets because only NHANES III contains household identification number, which was crucial for us to identify family relationships. Our initial data set was obtained by merging the household adult and examination data sets, and consisted of 20,050 subjects. All small families with less than three people have no sufficient information about parental status and thus were removed (77.26\%). We further excluded the 12 subjects with missing parental status, and our final data set consisted of 4,548 subjects (Figure 1). To account for the unequal probabilities of sampling selection, every subject carries a statistical weight that was assigned by NHANES. The final data set represented 187.52 million subjects after correcting for the sampling weights.

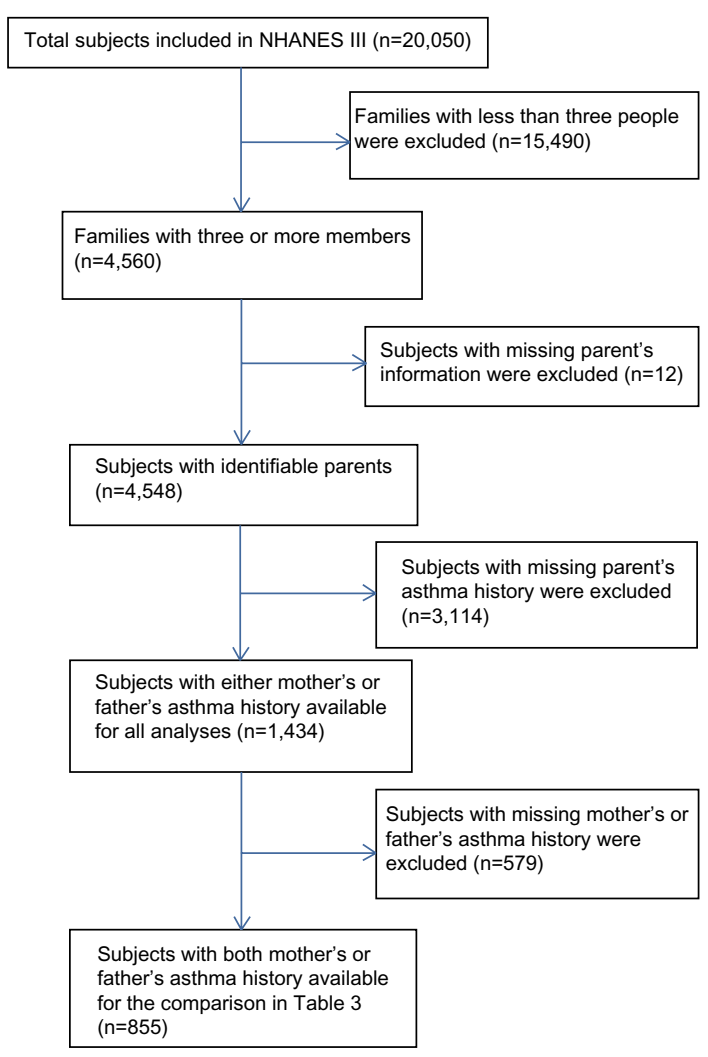

Figure I Study flow diagram. 


\section{Variables}

\section{Parent-child relationship}

Since there was no direct information available on familial and parental relationships, we used the individual's age, sex, and common household identification number to match each child participant to his/her parents. The parent-child relationships were also confirmed by checking the consistency between the child's answers to parents' disease history and the parental answers to their own health status related to asthma and heart attack.

\section{Asthma status of children and their parents}

The asthma status of children and their parents was based on their corresponding answers to the question, "Has a doctor ever told you that you had asthma?"

Age at onset of asthma of children and their parents The age at onset of asthma of children and their parents were based on their answer to the question, "How old were you when you were first told you had asthma?"

\section{Age at censoring of children and their parents}

For either children or parents who did not have asthma, they were considered as censored, and the age at censoring was their age at screening.

\section{Covariates of children}

Covariates included in analyses have been previously shown to influence baseline risk for asthma. The covariates we used were sex, race (White, Black, Other), poverty-income ratio $(<1, \geq 1$ ), obesity status (underweight, normal/overweight, obese), smoking in household (yes, no), and urbanization (yes, no) at the time of interview. Poverty-income ratio of each household was the ratio of the family income to the poverty threshold determined according to the corresponding regional income and expenses. The urbanization indicator was derived from the urbanization classification based on USDA rural/urban continuum codes. The obesity status of underweight, normal/overweight, and obese was derived according to body mass index $(\mathrm{BMI})<18.5,18.5-29.9$, and $\geq 30$, respectively. ${ }^{21}$

\section{Statistical analysis}

Following the guidelines from NHANES, we used the total NHANES III pseudo-PSU and the total NHANES III pseudostratum as the survey design parameters. Every variable except BMI was collected from the household interview, and the BMI variable was collected in the Mobile Examination Center (MEC). Therefore, we used the total interviewed sample final weight in the analysis without obesity status, and the total MEC examined sample final weight in the analysis with obesity status included.

To quantify parental history, we used a continuous standardized risk score - also called log-rank score - that incorporated parent's age at onset of asthma, and compared the results from using binary indicators. The calculation of the log-rank risk score in a survey data setting was revised from the score initially developed for cohort studies to reflect the complexity of the survey sampling design. First, we elaborate how the mothers' log-rank risk score was calculated. Let $T_{1}, T_{2}, \ldots, T_{d}$ be $d$ distinct time points of observed events for all mothers, let $Y_{m}$ denote whether the $m$ th mother has asthma or not, let $A_{m}$ denote the age at onset or at censoring for this mother, and $w_{m}$ the sampling weight for her. Then, during the $l$ th time period $\left(T_{l-1}, T_{p}\right)$, the risk of asthma for any mother is

$$
r_{l}=\frac{\sum_{m: A \in\left[T_{l-1, T_{l}}\right]^{w_{m}} I\left(Y_{m}=1\right)}}{\sum_{m: A_{m}>T_{l}}^{n} w_{m}}
$$

The numerator of $r_{l}$ is the weighted total number of events occurred in $\left(T_{1-1}, T_{1}\right)$, and the denominator denotes the weighted total number of events still at risk for all mothers. By dividing the weighted total number of cases of asthma that occurred during that time period by the mother population that were at risk, we have the risk of developing asthma during that time period for a mother. The log-rank risk score for a censored observation, $a_{0}^{k}$, in the $k$ th period is then the negative sum of the risk of asthma from the beginning up to the $k$ th period, ie, $a_{0}^{k}=-\sum_{l=1}^{k} r_{l}$, and the log-rank risk score for an observed event in the $k$ th period is $a_{1}^{k}=1+a_{0}^{k}$.

For fathers, the risk scores were calculated similarly in the population formed by all fathers. The separate calculation of mothers' and fathers' history score is intended to reflect the sex differences in asthma incidences.

Since the majority of the individuals' onset of asthma was before 30 years of age, the log-rank scores may not be sensitive to disseminate early age of onset. Thus, we modified the log-rank risk scores and further improved our estimation by using the weighted log-rank risk score. The calculation of the weighted log-rank risk score has the same setup as the log-rank risk scores. However, we weighted the risk of asthma during each time period by the inverse of the square root of the time. Now, the risk of asthma for any father/ mother during the $l$ th time period $\left(T_{1-1}, T_{1}\right)$ is $T_{l}^{-1 / 2} r_{l}$, and the weighted log-rank risk score for a censored observation in the $k$ th period is $a_{0}^{k}=-\sum_{l=1}^{k} T_{l}^{-1 / 2} r_{l}$, and for an observed event is $a_{1}^{k}=T_{k}^{-1 / 2}+a_{0}^{k}$. By using this weight, we put more 
weights on the earlier events, as people with an earlier onset of asthma should have a higher risk.

To select possible confounders, we first ran univariate Cox regression models, using sex, race, poverty-income ratio, obesity status, household smoking, and urbanization at interview as the sole predictor, respectively. If a factor was significant at the 0.05 level, it was included in the subsequent multivariate Cox model, with parental history of asthma as the primary predictor. The multivariate model was fit separately with one of the three definitions of parental asthma history: log-rank risk score, weighted log-rank risk score, and binary indicator, respectively. The analysis was performed for mother's asthma history and father's asthma history separately. However, the number of people with father's history available and the number of people with mother's history available was different. To make the sample size comparable, we further restricted our analysis to children with both parents' asthma history available. Proportional hazards assumptions were checked using graphical tools. Any covariate that violated the proportional hazards assumption was stratified accordingly in the multivariate analysis. All analyses were performed under the survey setting in STATA12 (College Station, TX, USA).

\section{Results}

Table 1 presents the summary statistics for the study data, both, for all participants in the original survey and for the

Table I Characteristics of all NHANES III subjects and our study subpopulation

\begin{tabular}{|c|c|c|}
\hline Characteristics & $\begin{array}{l}\text { All } \\
\text { (187.52 million) }\end{array}$ & $\begin{array}{l}\text { Subpopulation } \\
\text { (14.58 million) }\end{array}$ \\
\hline Age at interview & $43.25(0.40)$ & $36.33(0.34)$ \\
\hline \multicolumn{3}{|l|}{ Sex } \\
\hline Male & $89.49(47.72)$ & $8.18(56.11)$ \\
\hline Female & $98.03(52.28)$ & $6.40(43.89)$ \\
\hline \multicolumn{3}{|l|}{ Race } \\
\hline White & $157.72(84.1 \mathrm{I})$ & II.I6 (76.50) \\
\hline Black & $21.81(11.63)$ & $2.23(15.30)$ \\
\hline Other & $7.98(4.26)$ & $1.19(8.19)$ \\
\hline \multicolumn{3}{|l|}{ Poverty-income ratio } \\
\hline$\geq 1$ & I5I.86 (80.99) & $10.79(74.01)$ \\
\hline$<1$ & $22.43(11.96)$ & $2.12(14.55)$ \\
\hline \multicolumn{3}{|c|}{ Obesity status, based on body mass index } \\
\hline Underweight & $5.12(2.73)$ & $0.87(5.98)$ \\
\hline Normal/overweight & $14 \mid .75$ (75.59) & I I.38 (77.79) \\
\hline Obese & $40.48(21.59)$ & $2.36(16.10)$ \\
\hline \multicolumn{3}{|l|}{ Smoking in household } \\
\hline Yes & $68.32(36.44)$ & $7.29(49.97)$ \\
\hline No & $119.13(63.53)$ & $7.29(49.97)$ \\
\hline \multicolumn{3}{|l|}{ Urbanization } \\
\hline Yes & $91.62(48.86)$ & $7.73(52.99)$ \\
\hline No & $95.90(51.14)$ & $6.85(47.01)$ \\
\hline
\end{tabular}

Note: Estimated count in millions (percentage) for categorical variables and mean (standard error) for continuous variables for each category. subpopulation of individuals with parental asthma history available. Baseline characteristics of the populations were generally similar, suggesting no selection bias in the study population. One exception came from the distribution in sex, where the subpopulation included about $10 \%$ more males than the original data set. However, this potential bias does not affect our final analysis, which was stratified by sex.

The results of the univariate Cox regression are presented in Table 2 . The only significant covariate was obesity. The relative risks of asthma for the group of underweight people and for the group of obese people were 0.117 and 1.829, respectively, relative to the risk of asthma for the group of normal or overweight people. Males, African-Americans, and people with poverty-income ratio less than 1 tended to have higher risk for asthma, as observed in the literature, even though these effects were not significant in our sample. Smoking and urbanization were also not significant.

The Kaplan-Meier survival curves (ie, the probability of being unaffected with asthma) for each category of the risk factors tested are shown in Figure 2. The three obesity groups had clearly separated curves, with obese people having the lowest survival probability. Different categories of the other variables did not appear to cause distinct differences in survival probability. The proportional hazards assumptions were checked through plots of $-\log [-\log$ (survival) vs $\log ($ age) $]$ (as presented in Figure S1). There was no clear violation of proportional hazards assumptions for race, obesity status, household smoking, and urbanization. Because the $-\log (-\log ($ survival $))$ curves for males and females crossed around age 22 , sex violated the assumption and therefore was stratified upon in the subsequent analyses. Poverty-income ratio also violated the assumption, but given that it was nonsignificant even after stratification, it was not included in our final analysis.

Both the log-rank and weighted log-rank scores separated for mothers and fathers were roughly normally distributed. Also, the risk scores decreased monotonically with increasing age of onset, by definition (Figure S2). In addition, the middle range of log-rank score was approximately linear to age at onset of asthma, and one unit increase in the log-rank risk score corresponded to about a 10-year decrease in the age at onset.

Finally, Table 3 shows the results of the multivariate Cox regression model for assessing the separate effects of maternal and paternal history on offspring's asthma, adjusted for obesity status and stratified by sex of children. The top of Table 3 shows the results from the analysis on maximum available subjects, ie, subject with either father's or mother's asthma history available. Both maternal and paternal history 
Table 2 Association between potential risk factors and onset of asthma

\begin{tabular}{|c|c|c|c|c|}
\hline \multirow[t]{2}{*}{ Risk factor } & \multicolumn{2}{|c|}{ Estimated count $\times 10^{6}$ (percentage) } & \multirow[t]{2}{*}{ Hazard ratio $(95 \% \mathrm{Cl})$} & \multirow[t]{2}{*}{$P$-value } \\
\hline & With asthma (0.83) & Without asthma (13.76) & & \\
\hline \multicolumn{5}{|l|}{ Sex } \\
\hline Male & $0.42^{\mathrm{a}}(50.69)$ & $7.76^{b}(56.43)$ & $0.837(0.453,1.549)$ & 0.5648 \\
\hline Female & $0.4 I^{\mathrm{a}}(49.3 \mathrm{I})$ & $6.00^{\mathrm{b}}(43.57)$ & & \\
\hline \multicolumn{5}{|l|}{ Race } \\
\hline White & $0.61(73.67)$ & $10.55(76.67)$ & & \\
\hline Black & $0.18(21.46)$ & $2.05(14.93)$ & $1.385(0.854,2.245)$ & 0.1823 \\
\hline Other & $0.04(4.87)$ & 1.15 (8.39) & $0.583(0.128,2.65 I)$ & 0.4775 \\
\hline \multicolumn{5}{|c|}{ Poverty-income ratio at interview } \\
\hline$\geq 1$ & $0.54(65.78)$ & $10.25(74.50)$ & & \\
\hline$<1$ & $0.19(23.32)$ & $1.93(14.02)$ & I.77I $(0.737,4.256)$ & 0.1964 \\
\hline \multicolumn{5}{|c|}{ Obesity status at interview } \\
\hline Underweight & $4.36 \times 10^{-3}(0.55)$ & $0.87(6.29)$ & $0.117(0.025,0.54 I)$ & 0.0070 \\
\hline Normal/overweight & $0.56(69.91)$ & $10.92(78.25)$ & & \\
\hline Obese & $0.24(29.55)$ & $2.12(15.32)$ & $1.829(0.793,4.220)$ & 0.1532 \\
\hline \multicolumn{5}{|c|}{ Smoke in household at interview } \\
\hline Yes & $0.42(50.46)$ & $6.87(49.94)$ & $0.937(0.586,1.497)$ & 0.7803 \\
\hline No & $0.4 I(49.54)$ & $6.88(50.00)$ & & \\
\hline \multicolumn{5}{|l|}{ Urbanization at interview } \\
\hline Yes & $0.37(45.03)$ & $7.36(53.46)$ & $0.758(0.388,1.478)$ & 0.4080 \\
\hline No & $0.45(54.97)$ & $6.40(46.54)$ & & \\
\hline
\end{tabular}

Notes: ${ }^{a}$ Values of each group in the column add up to 0.83 ; bvalues of each group in this column add up to 13.76 .

had a significant impact on the onset of asthma in the second generation, using all three methods of quantifying disease history. However, the sample sizes in the two groups were quite different, and thus we were not able to compare the effect of paternal history and maternal history using these populations.
The bottom of Table 3 shows the more comparable results using the partial cohort in which both parents' asthma history was available. In this smaller cohort, paternal history became insignificant, while the impact of maternal history remained significant. Using the binary indicator to quantify parental
A
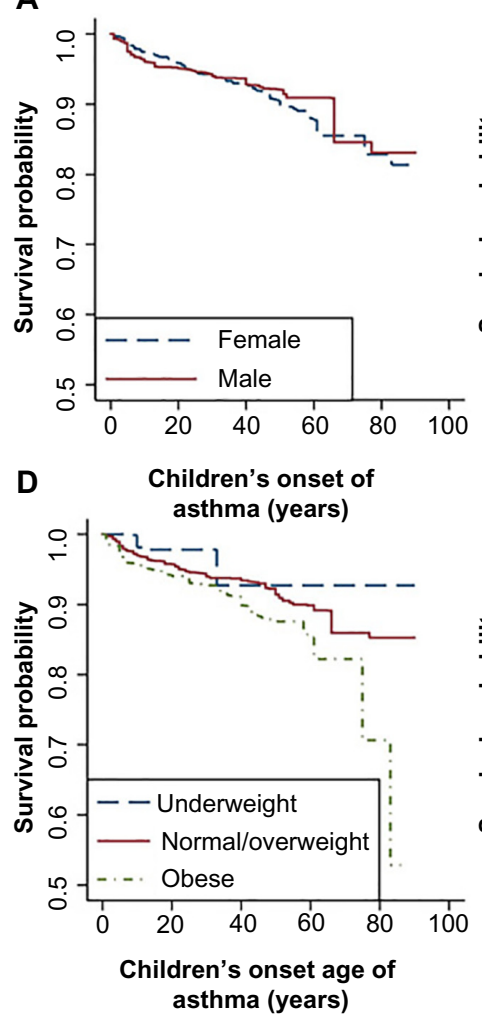

B

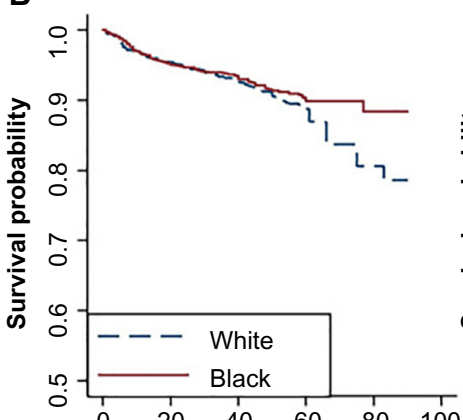

E

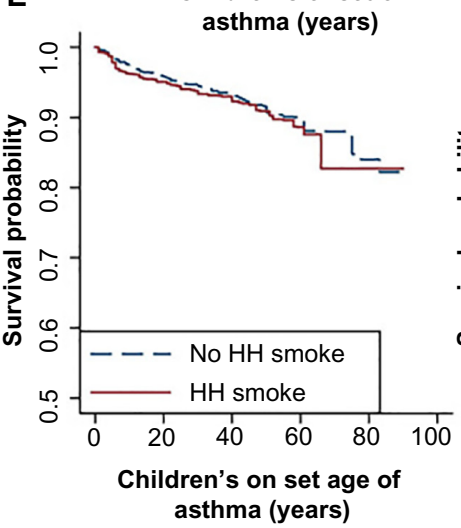

C

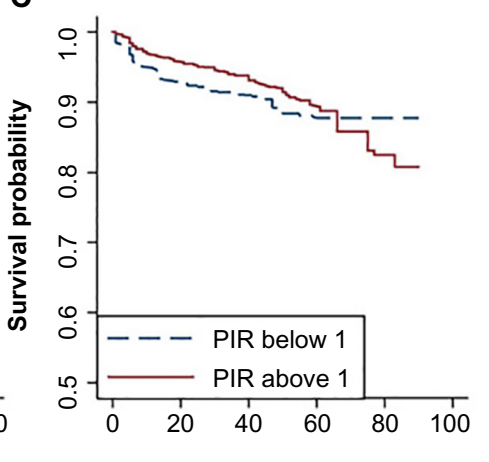

$\mathbf{F}$

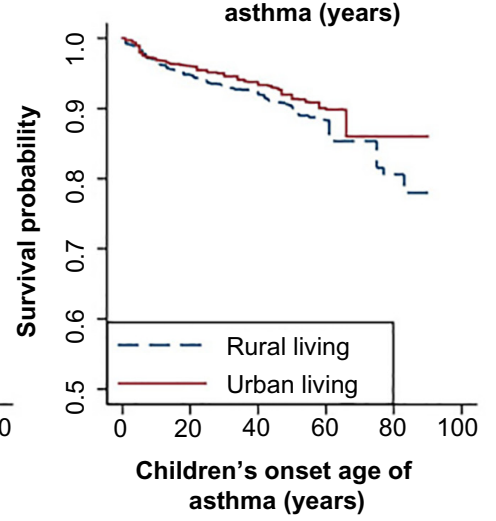

Figure 2 Kaplan-Meier curves for all categories of 6 candidate risk factors: sex (A), race (B), poverty income ratio (C), BMI (D), household smoking (E), and urbanization (F). Abbreviations: $\mathrm{HH}$, household; PIR, poverty-income ratio. 
Table 3 Association between parental history and asthma risk in the children, adjusting for obesity status

\begin{tabular}{|c|c|c|c|c|}
\hline \multirow[t]{2}{*}{ Type of indicator } & \multicolumn{2}{|l|}{ Father (1 0.53 million) } & \multicolumn{2}{|l|}{ Mother ( 13.12 million) } \\
\hline & Hazard ratio $(95 \% \mathrm{Cl})$ & $P$-value & Hazard ratio $(95 \% \mathrm{Cl})$ & $P$-value \\
\hline \multicolumn{5}{|c|}{ Father's or mother's asthma history available } \\
\hline Binary indicator & $3.012(1.124,8.074)$ & 0.0292 & $4.372(1.699,11.250)$ & 0.0029 \\
\hline Log-rank risk score & $1.227(0.993,1.517)$ & 0.0579 & $1.267(1.074,1.494)$ & 0.0058 \\
\hline \multirow[t]{3}{*}{ Weighted log-rank risk score } & $1.931(1.062,3.509)$ & 0.0316 & $2.955(1.935,4.515)$ & $4.8 \times 10^{-6}$ \\
\hline & \multicolumn{2}{|l|}{ Father (9.04 million) } & \multicolumn{2}{|l|}{ Mother (9.04 million) } \\
\hline & Hazard ratio $(95 \% \mathrm{Cl})$ & $P$-value & Hazard ratio $(95 \% \mathrm{Cl})$ & $P$-value \\
\hline \multicolumn{5}{|c|}{ Father's and mother's asthma history available } \\
\hline Binary indicator & $2.165(0.691,6.788)$ & 0.1805 & $3.714(1.189,11.600)$ & 0.0249 \\
\hline Log-rank risk score & $1.215(0.976,1.512)$ & 0.0801 & $1.373(1.113,1.694)$ & 0.0038 \\
\hline Weighted log-rank risk score & $1.76 \mid(0.929,3.339)$ & 0.0815 & $3.210(1.863,5.533)$ & 0.0001 \\
\hline
\end{tabular}

history, we can conclude that the relative risk of asthma for people whose mother had asthma relative to people whose mother did not have asthma is 3.714 (95\% CI: 1.189-11.600). The interpretation of the results using log-rank risk score is different from that of binary indicator, given the continuous scale. Because a one unit increase in the log-rank risk score corresponded to about a 10-year decrease in the parent's age at onset of asthma (Figure S2), the hazard of asthma for offspring increased by 1.373 -fold for an approximately 10 -year decrease in mother's age at onset of asthma. Thus, we concluded that maternal history was strongly associated with the onset of asthma, but the paternal history had a smaller effect on the onset of asthma in the second generation that was only detectable in large samples.

We also generated Kaplan-Meier curves for the covariate of parental history, stratified by the children's sex (Figures 3 and 4). Male offspring whose mother or father had asthma had lower survival probability than those whose mother or father did not have asthma (Figure 3). The separation of the two survival curves was larger between those with and without mother's history. Male offspring whose parents had earlier age at onset had a higher risk (Figure 3A and 3C).

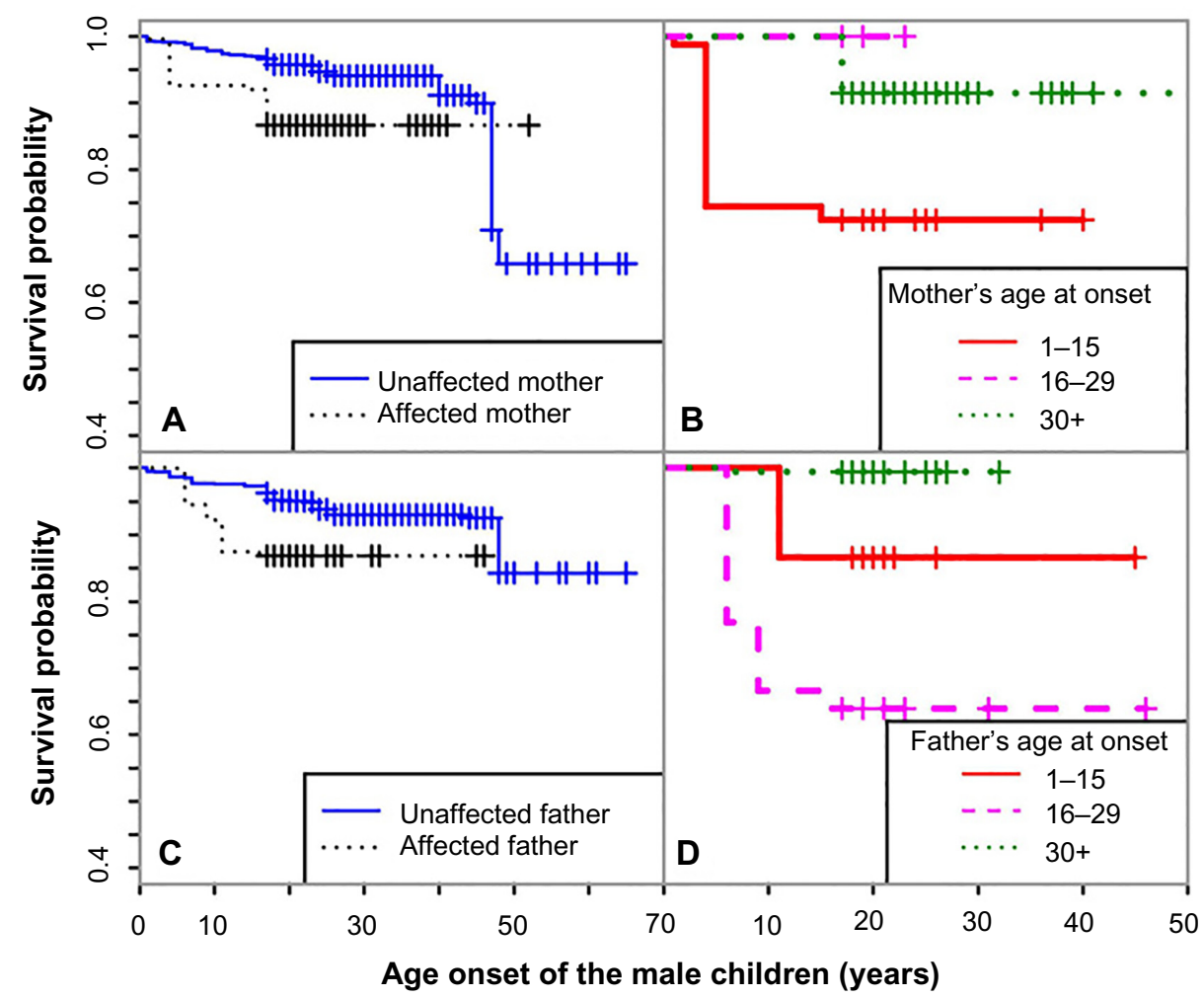

Figure 3 Kaplan-Meier curves for male children across groups with different parental risks, between male children with affected and unaffected mothers (A), between male children with affected mothers with increasing age of onset (B), between male children with affected and unaffected fathers (C), and between male children with affected fathers with increasing age of onset (D). 


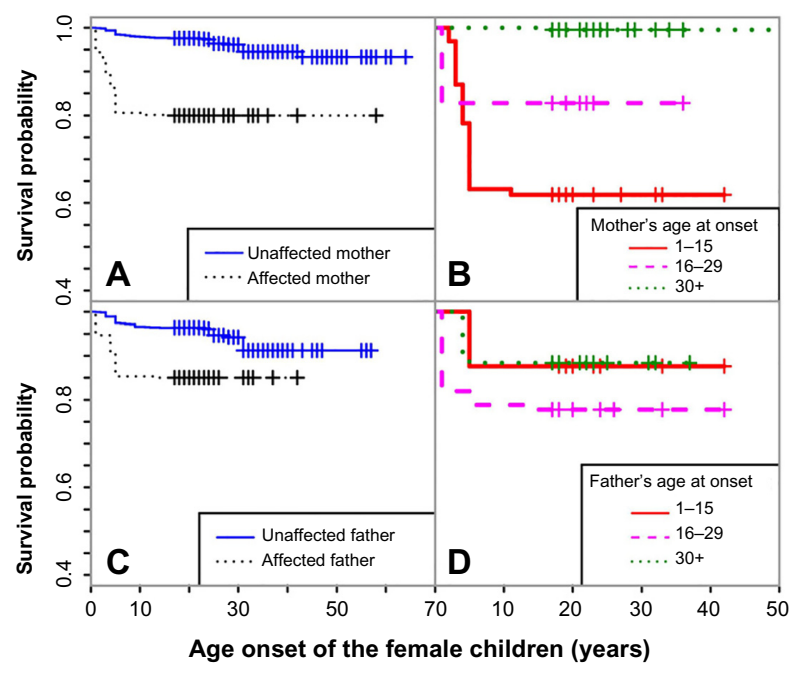

Figure 4 Kaplan-Meier curves for female children across groups with different parental risks, between female children with affected and unaffected mothers (A), between female children with affected mothers with increasing age of onset (B), between female children with affected and unaffected fathers (C), and between female children with affected fathers with increasing age of onset (D).

The risk difference between the boys with and without maternal history was comparable to that between the boys with and without paternal history. However, if the affected mother had early age of onset, the risk for the boys are much higher than those with later age of onset (Figure 3B). The trend for the boys' risk due to increased paternal age of onset was not that clear.

We detected a similar trend for female offspring (Figure 4) as in male offspring (Figure 3); however, the gap between the survival curves, using the binary indicator, was smaller. We also noticed that female offspring whose parents had earlier age at onset did not necessarily have lower survival probabilities. As Figure 4 shows, the survival probability for female offspring whose father had asthma between the ages of 16 and 29 years was lower than those whose father had asthma between the ages of 1 and 15 years.

\section{Discussion}

Our study has demonstrated that the impact of the maternal history on onset of asthma in children is different from that of the paternal history: mother's asthma history was strongly associated with the children's onset of asthma. Using the binary indicator to quantify parental history, we concluded that the lifetime relative risk of asthma for people whose mother had asthma relative to people whose mother did not have asthma is 3.714. In addition, based on the log-rank risk score, the hazard of asthma for the offspring increased by 1.373-fold for an approximately 10 -year decrease in mother's age of onset of asthma. Some past research supported our conclusion that maternal history has a stronger association with children's asthma risk than paternal history. ${ }^{16,17}$ In a cross-sectional study of 499 US families recruited between 1994 and 1996, the risk of childhood asthma associated with maternal asthma history was higher than that associated with paternal asthma history. ${ }^{16}$ The odds ratio for asthma in a child with maternal asthma history versus that for a child with no maternal asthma history was 4.1 , while the odds ratio for asthma in a child with paternal asthma history versus that for a child with no paternal asthma history was only 2.7. ${ }^{16}$ Others found no apparent difference between the impact of maternal and paternal history. ${ }^{12,22}$ Based on the data on subjects aged 20 years or older from the NHANES between 1999 and 2004, Liu et a ${ }^{12}$ found no significant difference between the impact of maternal and paternal asthma history on children's asthma status using a logistic regression model, without accounting for the familial correlation and age of onset of children and their parents.

The main strength of our study was the novel use of the logrank and weighted log-rank risk scores to quantify the impact of parental history, which incorporated the parent's age at onset of asthma and improved the prediction of risk in the second generation. The finding about the effect of parents' age onset was not previously reported. Compared with the traditional binary indicators, our risk scores provided a smaller standard error and more precise estimate of parental history.

Because our data set was from a national survey, which was not intended to study the family history impact on diseases, we were not able to obtain direct information on biological parents, parental asthma status, parent's age at onset of asthma, and covariate values at the time of the onset of asthma. Therefore, the variables that we used for the parent's asthma status and age at onset were estimates that we derived from the data set, using information on age, sex, and household identification number. Given the historical nature of the data, we cannot validate the derived relationship and, thus, might have introduced bias by inferring this parent relationship. However, if we assume the error is random, then our conclusions are still valid. In addition, it is possible that more precise matching of parents to children might further improve the accuracy of our estimates. Our study used data collected from 1988 to 1994 because family information is not publicly available in later surveys.

Another limitation of this data set was that the values of the time-varying variables, including household smoking, obesity status, urbanization, and poverty-income ratio, only reflected the status at the time of the interview rather than 
at the time of onset of asthma. This might explain why the hazard ratios for smoking in household and urbanization were not consistent with the findings in the existing literature. Children exposed to household (second-hand) smoking have previously been found to have a higher asthma incidence, ${ }^{6}$ and exposure to urban air pollution containing fine particulate matter (PM2.5) and sulfur dioxide $\left(\mathrm{SO}_{2}\right)$, major components in automobile exhausts, likely also contribute to asthma risk. ${ }^{7}$ Our discrepant results seemed to indicate that families who have children with asthma tend to change their life styles, such as moving from the city to the suburbs or reducing household smoke. However, such positive changes would have to happen in a large percentage of individuals to cause a direction change between risk factors and the disease. On the other hand, although the obesity status was also recorded at the time of the survey interview, it has been shown that childhood and adolescent obesity tend to persist into adulthood. ${ }^{23}$ The direction and magnitude of the obesity effects in our study were consistent with the obesity risk in published literature, ${ }^{8}$ where $29.55 \%$ of people affected with asthma were obese and only $15.32 \%$ of unaffected were obese. One potential mechanism for this may be increased lung inflammatory responses in obese individuals. ${ }^{9}$ Our result also showed that underweight people had a lower risk of asthma. This associations has been shown in various studies. ${ }^{24,25}$

The age at interview ranges from 1 to 68 years, with the first, second, and third quantile of 18, 21, and 26 years old, respectively. The younger the person was at the time of NHANES interview, the shorter this person's health history was and the lower chance his/her asthma onset can be observed. As children got older and moved out of the household, they may be underreported in the national survey.

Our study has identified maternal asthma history to be strongly associated with the onset of asthma in the second generation, and by using the log-rank risk scores that incorporated the age at onset of parent's asthma, we found that children whose mothers had an earlier age at onset had an increased risk of asthma. Future studies with alternate data sources will be needed to confirm the associations we have identified. It would also be helpful to explore the genetic factors behind the parent-of-origin effect to help further understand the mechanisms of asthma inheritance.

\section{Acknowledgment}

The study was supported by the National Institutes of Health grant R01GM088566.

\section{Disclosure}

The authors report no conflicts of interest in this work.

\section{References}

1. Pearce N, At-Khaled N, Beasley R, et al. Worldwide trends in the prevalence of asthma symptoms: phase III of the International Study of Asthma and Allergies in Childhood (ISAAC). Thorax. 2007;62: 758-766.

2. Ripabelli G, Tamburro M, deSammarco ML, et al. Asthma prevalence and risk factors among children and adolescents living around an industrial area: a cross-sectional study. BMC Public Health. 2013;13:1038.

3. Moorman J, Zahran H, Truman BI, et al. Current asthma prevalence United States, 2006-2008. MMWR Surveill Summ. 2011;60:84-86.

4. Tantisira KG, Colvin R, Tonascia J, et al. Airway responsiveness in mild to moderate childhood asthma: sex influences on the natural history. Am J Respir Crit Care Med. 2008;178(4):325-331.

5. Voraphani N, Stern DA, Wright AL, et al. Risk of current asthma among adult smokers with respiratory syncytial virus illnesses in early life. Am J Respir Crit Care Med. 2014;190(4):392-398.

6. Goodwin RD, Cowles RA. Household smoking and childhood asthma in the United States: a state-level analysis. J Asthma. 2008;45(7): 607-610.

7. Gorai AK, Tuluri F, Tchounwou PB. A GIS based approach for assessing the association between air pollution and asthma in New York State, USA. Int J Environ Res Public Health. 2014;11(5):4845-4869.

8. Sybilski AJ, Raciborski F, Lipiec A, et al. Obesity-a risk factor for asthma, but not for atopic dermatitis, allergic rhinitis and sensitization. Public Health Nutr. 2015;18(3):530-536.

9. Kim SH, Sutherland ER, Gelfand EW. Is there a link between obesity and asthma? Allergy Asthma Immunol Res. 2014;6(3):189-195.

10. Rodríguez de la Vega A, Tejeiro Fernández A, Gómez Echeverría A, et al. Investigation of the prevalence and inheritance of bronchial asthma in San Antonio de los Baños, Cuba. Bull Pan Am Health Organ. 1975;9(3):221-231.

11. Burke W, Fesinmeyer M, Reed K, et al. Family history as a predictor of asthma risk. Am J Prev Med. 2003;24:160-169.

12. Liu T, Valdez R, Yoon PW, et al. The association between family history of asthma and the prevalence of asthma among US adults: National Health and Nutrition Examination Survey, 1999-2004. Genet Med. 2009;11(5):323-328.

13. Sharma S, Zhou X, Thibault DM, et al. A genome-wide survey of $\mathrm{CD} 4(+)$ lymphocyte regulatory genetic variants identifies novel asthma genes. J Allergy Clin Immunol. 2014;134(5):1153-1162.

14. Peters JL, Boynton-Jarrett R, Sandel M. Prenatal environmental factors influencing IgE levels, atopy and early asthma. Curr Opin Allergy Clin Immunol. 2013;13(2):187-192.

15. Tang WY, Levin L, Talaska G, et al. Maternal exposure to polycyclic aromatic hydrocarbons and 5'-CpG methylation of interferon- $\gamma$ in cord white blood cells. Environ Health Perspect. 2012;120(8):1195-1200.

16. Litonjua AA, Carey VJ, Burge HA, et al. Parental history and the risk for childhood asthma. Does mother confer more risk than father? Am J Respir Crit Care Med. 1998;158(1):176-181.

17. Withers NJ, Low L, Holgate ST, et al. The natural history of respiratory symptoms in a cohort of adolescents. Am J Respir Crit Care Med. 1998;158:352-357.

18. Dold S, Wjst M, von Mutius E, et al. Genetic risk for asthma, allergic rhinitis, and atopic dermatitis. Arch Dis Child. 1992;67:1018-1022.

19. Ronmark E, Jonsson E, Platts-Mills T, et al. Different pattern of risk factors for atopic and nonatopic asthma among children: report from the Obstructive Lung Disease in Northern Sweden Study. Allergy. 1999;54:926-935. 
20. Feng R, McClure L, Tiwari HK, et al. A new estimate of family disease history providing improved prediction of disease risks. Stat Med. 2009;28(8):1269-1283.

21. Centers for Disease Control and Prevention. Healthy weight - it's not a diet, it's a lifestyle. Available at: http://www.cdc.gov/healthyweight/ assessing/bmi/adult_bmi/index.html?s_cid=tw_ob064. Accessed August 25, 2014.

22. Bjerg A, Hedman L, Perzanowski MS, et al. Family history of asthma and atopy: in-depth analyses of the impact on asthma and wheeze in 7- to 8-year-old children. Pediatrics. 2007;120(4):741-748.
23. Serdula MK, Ivery D, Coates RJ, Freedman DS, Williamson DF, Byers T. Do obese children become obese adults? A review of the literature. Prev Med.1993;22(2):167-177.

24. Mebrahtu TF, Feltbower RG, Greenwood DC, Parslow RC. Childhood body mass index and wheezing disorders: a systematic review and meta-analysis. Pediatr Allergy Immunol. 2015;26(1):62-72.

25. Lang JE, Hossain J, Smith K, Lima JJ. Asthma severity, exacerbation risk, and controller treatment burden in underweight and obese children. JAsthma. 2012;49(5):456-463. 


\section{Supplementary material}

A

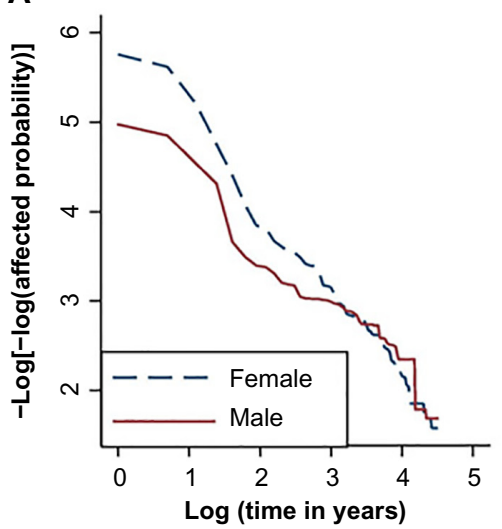

D

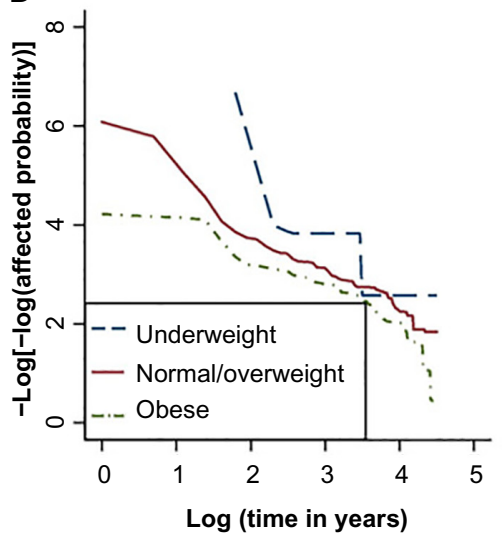

B

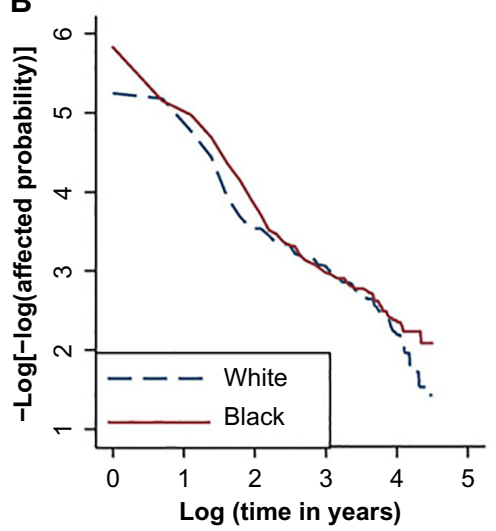

E

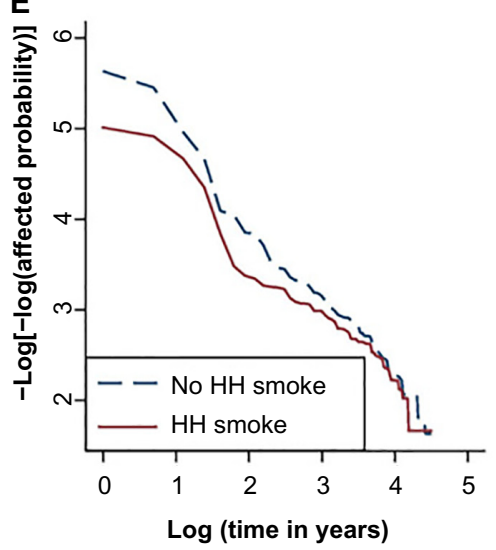

C

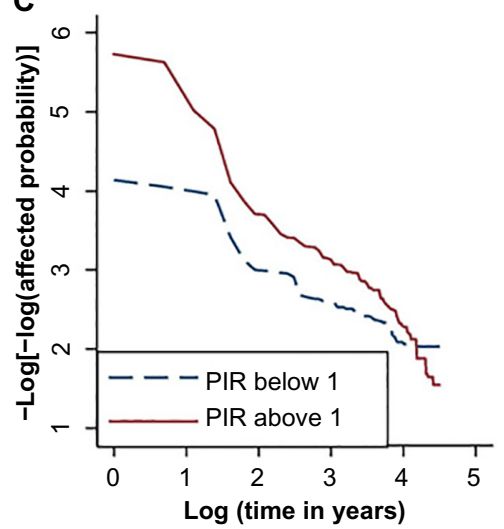

$\mathbf{F}$

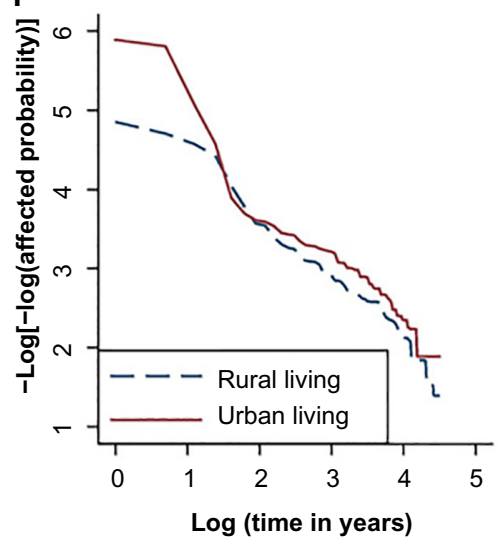

Figure SI Log-log(survival) versus log(age) for checking the proportional hazards assumption. Abbreviations: $\mathrm{HH}$, household; PIR, poverty-income ratio. 


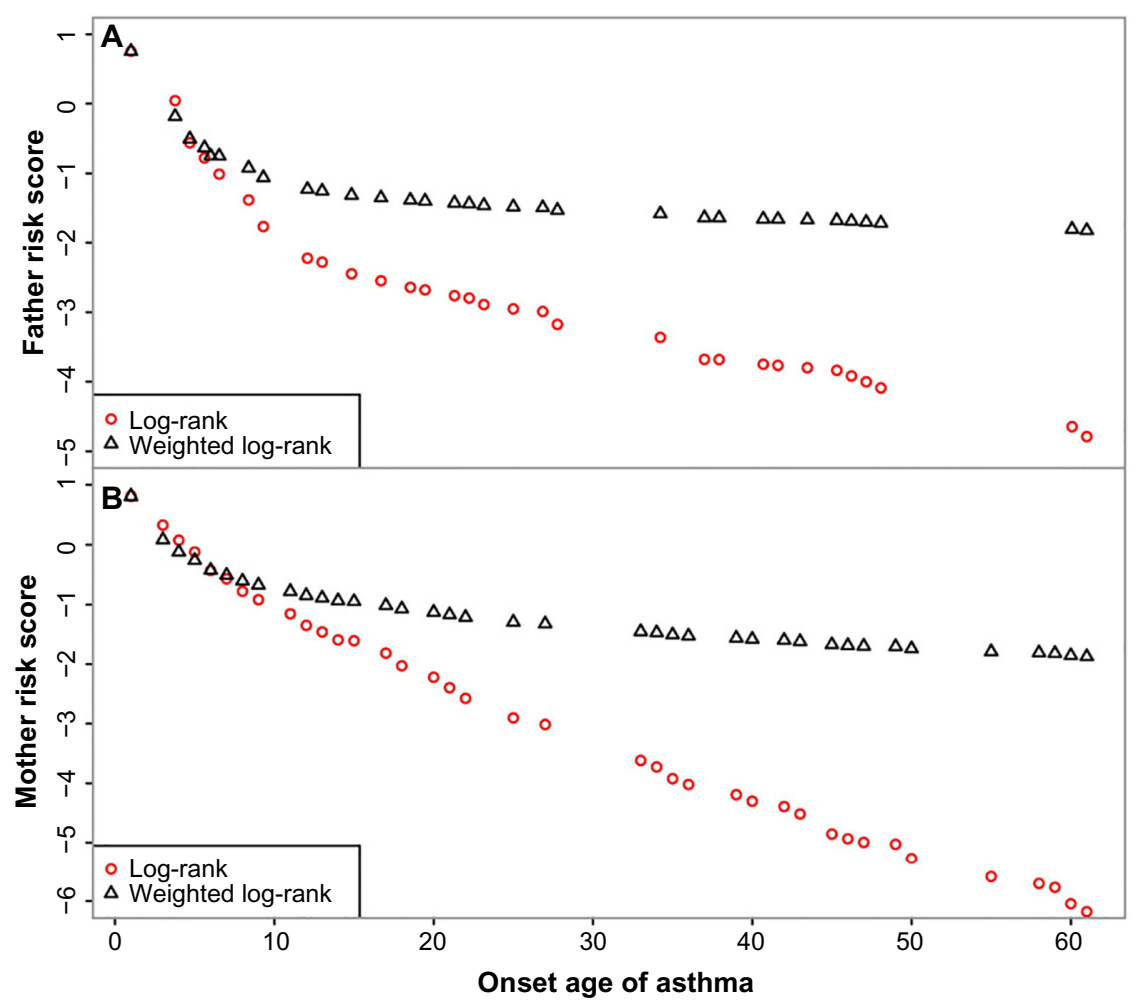

Figure S2 Relationship of proposed risk scores and age at onset of asthma.

Note: A one-unit increase in the log-rank risk score corresponds to about a 10-year decrease in the parent's age at onset of asthma.

\section{Publish your work in this journal}

The Journal of Asthma and Allergy is an international, peer-reviewed open-access journal publishing original research, reports, editorials and commentaries on the following topics: Asthma; Pulmonary physiology; Asthma related clinical health; Clinical immunology and the immunological basis of disease; Pharmacological interventions and new therapies. Issues of patient safety and quality of care will also be considered. The manuscript management system is completely online and includes a very quick and fair peer-review system, which is all easy to use. Visit http://www.dovepress.com/testimonials.php to read real quotes from published authors.

Submit your manuscript here: http://www.dovepress.com/journal-of-asthma-and-allergy-journal 